\title{
Correction to: Farmers' perceptions and matching climate records jointly explain adaptation responses in four communities around Lake Tana, Ethiopia
}

András Darabant ${ }^{1} \cdot$ Birgit Habermann ${ }^{1} \cdot$ Kibruyesfa Sisay $^{2} \cdot$ Christopher Thurnher $^{2}$. Yonas Worku $^{3} \cdot$ Selamawit Damtew $^{4} \cdot$ Mara Lindtner $^{1} \cdot$ Leisa Burrell $^{1} \cdot$ Abrham Abiyu $^{5}$

Published online: 7 November 2020

(C) Springer Nature B.V. 2020

\section{Correction to: Climatic Change https://doi.org/10.1007/s10584-020-02889-x}

The original article has been corrected. Unfortunately, the original publication contained a mistake in one of the author names. The correct name is Kibruyesfa Sisay.

Publisher's note Springer Nature remains neutral with regard to jurisdictional claims in published maps and institutional affiliations.

The online version of the original article can be found at https://doi.org/10.1007/s10584-020-02889-x

András Darabant

andras.darabant@boku.ac.at

Extended author information available on the last page of the article 


\section{Affiliations}

András Darabant ${ }^{1} \cdot$ Birgit Habermann ${ }^{1} \cdot$ Kibruyesfa Sisay $^{2} \cdot$ Christopher Thurnher $^{2}$. Yonas Worku ${ }^{3} \cdot$ Selamawit Damtew $^{4} \cdot$ Mara Lindtner $^{1} \cdot$ Leisa Burrell $^{1} \cdot$ Abrham Abiyu $^{5}$

Birgit Habermann

bhaberma@gmail.com

Kibruyesfa Sisay

kibru122@yahoo.com

Christopher Thurnher

christopher.thurnher@gmail.com

Yonas Worku

yonas.worku@yahoo.com

Selamawit Damtew

selamawit.damtew@gmail.com

Mara Lindtner

mara.lindtner@gmx.at

Leisa Burrell

leisa.burrell@gmail.com

Abrham Abiyu

abrham.abiyu@gmail.com

1 Department of Sustainable Agricultural Systems, Institute for Development Research, BOKU University, Peter-Jordan-Straße 76/I, 1190 Vienna, Austria

2 Department of Forest and Soil Sciences, Institute of Silviculture, BOKU University, Peter Jordan Strasse 82, 1190 Vienna, Austria

3 Gondar Agricultural Research Centre, Gondar, Amhara, Ethiopia

4 Bahir Dar University, Bahir Dar, Amhara, Ethiopia

5 Amhara Regional Agricultural Research Centre, Bahir Dar, Amhara, Ethiopia 